\title{
Information Communication Technology Revolutionizing Tourism
}

\author{
DIMITRIOS BUHALIS and PETER O'CONNOR
}

\begin{abstract}
This paper identifies a number of key changes in Information Communication Technologies (ICT) that gradually revolutionize the tourism industry. E-tourism and the Internet in particular support the interactivity between tourism enterprises and consumers and as a result they re-engineer the entire process of developing, managing and marketing tourism products and destinations. All stakeholders related to tourism and hospitality, therefore, gradually see their role being changed and new opportunities and challenges emerging. The paper demonstrates that future of e-Tourism will be focused on consumer centric technologies to ensure that the new sophisticated and experienced consumers are served. Therefore, agile strategies are required at both strategic and tactical management levels to develop the 'infostructure' for tourism organizations to manage their internal functions, their relationships with partners and their interactions with all stakeholders including consumers. Only those organizations that appreciate the opportunities which ICTs bring and manage their resources successfully will be able to enhance their innovation and competitiveness in the future.
\end{abstract}

Keywords: strategic tourism management and marketing, ICTs, e-tourism, customer centric, value chain, networks.

\section{Introduction}

Information Communication Technologies (ICTs) have been transforming tourism globally. The ICT driven reengineering has gradually generated a new paradigm-shift, altering the industry structure and developing a whole range of opportunities and threats. ICTs empowers consumers to identify, customize and purchase tourism products and supports the globalization of the industry by providing tools for developing, managing and distributing offerings worldwide. Increasingly, ICTs play a critical role for the competitiveness of tourism organizations and destinations (Buhalis 1998, 2003; O'Connor1999; Sheldon 1997; Poon 1993). ICTs are becoming a key determinant of organizational competitiveness and a wide range of technological developments propel this evolution. Successful ICT deployment requires innovative management to constantly review developments and adopt suitable technological solutions in order to maximize organizational competitiveness.

\section{Technological Developments and ICT Empowered Change}

Major hardware developments, include massive enhancements in processing capabilities, allow computers to handle complex algorithms with a constantly increasing speed of computation (Beekman 2003). This allows organizations to centralize ICTs to units that control the entire organization and to outsource selected non-core functions to specialists businesses which may simply host data or applications or handle the entire process. Scalable and 'on demand' technologies also allow organizations to switch computation power between applications, according to dynamic demand. The combination of enhancements in processing and flexibility of processing capability allows organizations to use their resources more wisely and profitably. Nano-technologies facilitate the minimization of hardware and its mass production, reducing production costs and improves the portability of devices. Nanoelectronics can provide the high-technology at low manufacturing cost and will eventually make systems become invisible and 'disappear' into the background. The development of mobile and portable devices, from laptops and tablet PCs to PDAs (Personal Digital Assistants) and Smart Phones also offer significant computation power, storage and portability. Tablets are increasingly developing interfaces that simulate notebooks and palmtops and PDAs offer lightweight portable computing. As the distinction between PDAs and mobile phones increasingly becomes blurred, people will soon carry a device that incorporates both a mobile phone and a fairly powerful and permanently

DIMITRIOS BUHALIS is Programme Leader MSc in Tourism Marketing, School of Management, University of Surrey, Guildford GU2 7XH, England, UK. e-mail: d.buhalis@surrey.ac.uk 
connected personal computer, enabling both voice and data communications.

Extensive networking is growing both within and between partner organizations (Amor 2002). The proliferation of the Internet, Intranets and Extranets supports communications between employees, units, organizations, as well as with external partners and consumers. Intranets and Enterprise Resource Planning (ERP) systems provided inter-organizational between processes, departments and functions enable enterprises to reduce labour cost, systems that support an integrated electronic infrastructure. Synergies and interoperability increase efficiency, enhance responsiveness and make better informed decisions. This empowers employees to improve their performance, increasing internal efficiency and effectiveness. Intraorganizational networking emerged through 'extranets', which enhances interactivity and interoperability between organizations and trusted partners. By linking and sharing data and processes electronically, organizations formulate alliances to build complementary services, expand reach and enhance collaboration. The Internet empowered the distribution of multimedia applications, such as textual data, graphics, pictures, videos, and sounds. Search engines such as Google and Yahoo provided unprecedented capability to find anything, including destination and product information. An electronic marketplace has gradually emerged and suppliers have developed Internet interfaces to communicate with clientele and partners to sell directly. New intermediaries also emerge to take advantage of the capabilities of the Internet and aggregate products through dynamic packaging.

The huge increase in digital information sent and received by households and businesses requires an increase in bandwidth. Broadband provides fast 'always on' access to services, applications and content resulting in lifestyle and productivity benefits. Despite the initial massive investment required in new networks and infrastructure as well as the development of new content, services and applications, broadband is expanding rapidly (EU 2001). Broadband access is mostly charged based on flat access fees, resulting in both the expansion of time people spend online and e-commerce involvement. Wireless and Mobile networks have also developed to allow access everywhere. The Global System for Mobile Communication (GSM) and the Wireless Application Protocol (WAP) allowed the communication of voice and data over mobile phones. General Packet Radio Service (GPRS) and Universal Mobile Telecommunications System (UMTS) as well as I-Mode in Japan introduce third generation (3G) mobile services, empowering multimedia communications on mobile devices. In addition, Wireless Local Area Networks (WLANs) allow connectivity of portable devices through wireless-radio connections (WiFi), whilst Bluetooth connects devices over short distances (Figure 1). Wireless LANs have limited area coverage whilst 3G networks enable continuous data transmission on the move. Increasingly, devices are equipped with Bluetooth, WiFi and $3 \mathrm{G}$ capabilities and each technology will be used according to requirements, location and costs.

The development of Digital Television will effectively bring the Internet to the living room of most families. User friendly interfaces based on an advanced television set will be easily operated through a simplified keyboard that will enable the vast majority of the population to have direct access to organizations electronically. This will bring electronic commerce to the mass digital market.

Werthner and Klein (1999) have identified the most significant technological developments forcing a new wave of technological evolution (Figure 2). The underlying trend

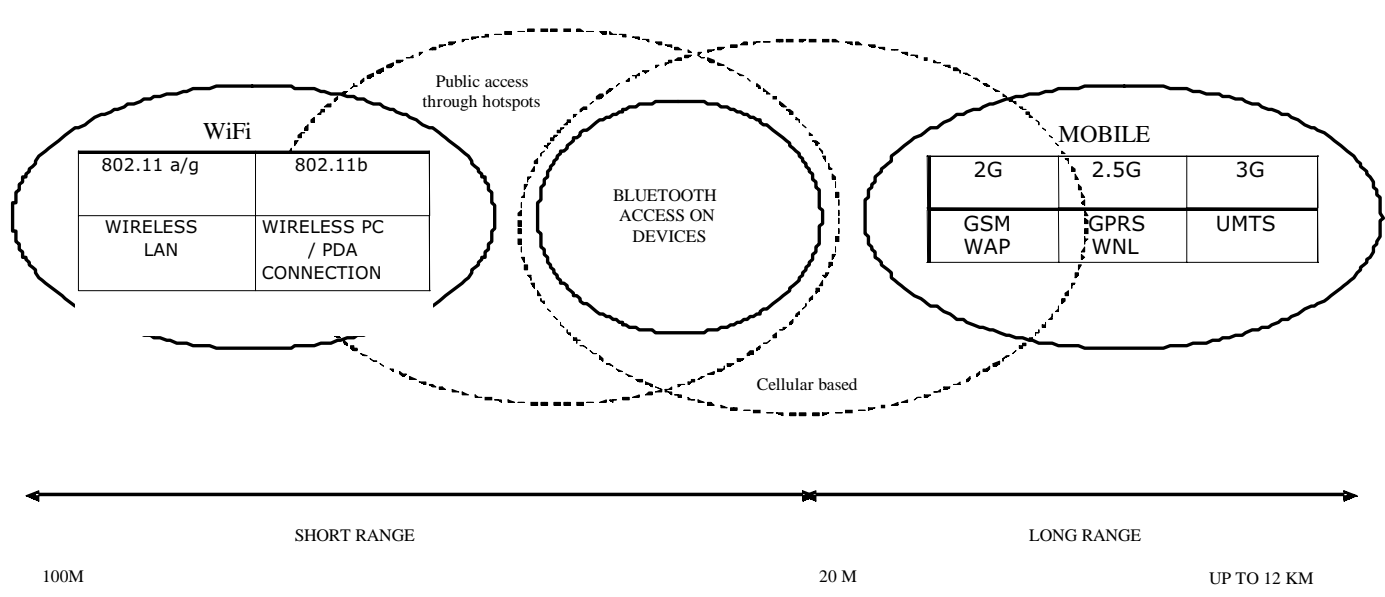

Figure 1. Wireless Technologies and Interlines 
of all developments is the integration of hardware, software and intelligent applications through networking and advanced user interfaces. Technological convergence leads developments and only blurred boundaries between systems exist to illustrate dependencies and relationships. However, all technologies need improvements in order to enhance their speed, inter-operability, reliability and adaptation to the industry and consumer needs. Fast and reliable networks need to emerge to support media rich applications and online video presentations. Information Management supported by object-oriented, relational databases are required to enable inter-linking between all the information kept by organizations to generate synergies. Data modelling and knowledge management must enhance the use of operational data in the decision-making processes and enable better informed operational and strategic choices. Intelligent applications need to incorporate knowledge from all sections of organization, use simulation techniques and the processing of statistics to improve the quality of information used for decision making and enable organizations to adopt more proactive approaches to management and marketing problems. Knowledge discovery and data mining support management and marketing functions whilst learning systems and agents increasingly accumulate and use knowledge productively to support employees and organizations.
User-friendly interfaces enable non-specialists to use computers without extensive training. Adaptive interfaces and the visualization of computing functions simplify processes and empower users to take advantage of systems and applications. Finally, integration of all applications and systems support interoperability on different platforms and through different media. Werthner and Klein (1999: 29) define interoperability as the provision of a well defined and endto-end service, in a consistent and predictable way. This covers not only technical features, but also for example in the case of electronic market environments, contractual features as well as a set of institutional rules'. Integration enables end-users to access a broad knowledge basis and empowers suppliers to appreciate the information as well as product and service needs of consumers and partners.

Perhaps the next major revolution will emerge in the form of Ambient Intelligence defined by ISTAG (2003) as 'a set of properties of an environment that we are in the process of creating'. This represents a new paradigm for how people can work and live together. According to the ISTAG vision statement, humans will, in an Ambient Intelligent Environment, be surrounded by intelligent interfaces supported by computing and networking technology that is embedded in everyday objects, such as furniture, clothes, vehicles, roads and smart materials - even particles of decorative substances like paint. Humans will live in an

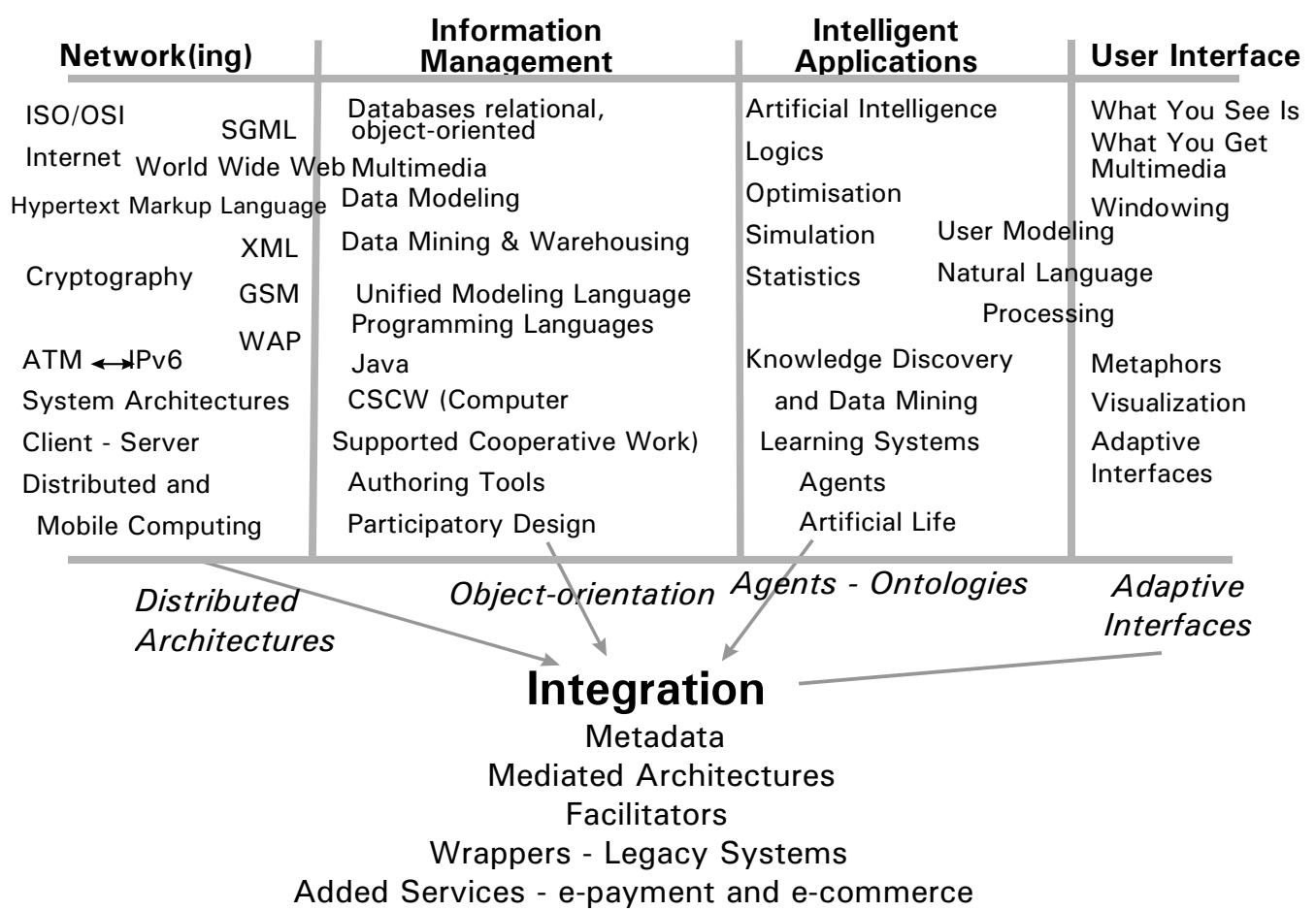

Figure 2. Lines of technological evolution

Source: Adapted from Werthner and Klein 1999 
Ambient Intelligence Space in which there will be seamless interoperation between different environments - home, vehicle, public space, work, leisure space, tourism destination etc. This implies a seamless environment of computing, advanced networking technology and specific interfaces which should be aware of the specific characteristics of human presence and personalities; adapt to the needs of users; be capable of responding intelligently to spoken or gestured indications of desire; and even result in systems that are capable of engaging in intelligent dialogue (Figure 3). Ambient Intelligence facilitates participation by the individual - in society, in a multiplicity of social and business communities, and in the administration and management of all aspects of their lives, from entertainment to governance. It should be unobtrusive and interaction should be relaxed and enjoyable rather than involve a steep learning curve. To be acceptable, Ambient Intelligence needs to be driven by humanistic concerns, not technologically determined ones and should be controllable by ordinary people.

Pursuit of the Ambient Intelligence vision will require contributions from many streams of research to realize both 'ambience' and 'intelligence'. The development of the Ambient Intelligence space will depend not simply on finding solutions to the research challenges for ambience and intelligence, but on the extent to which mechanisms can

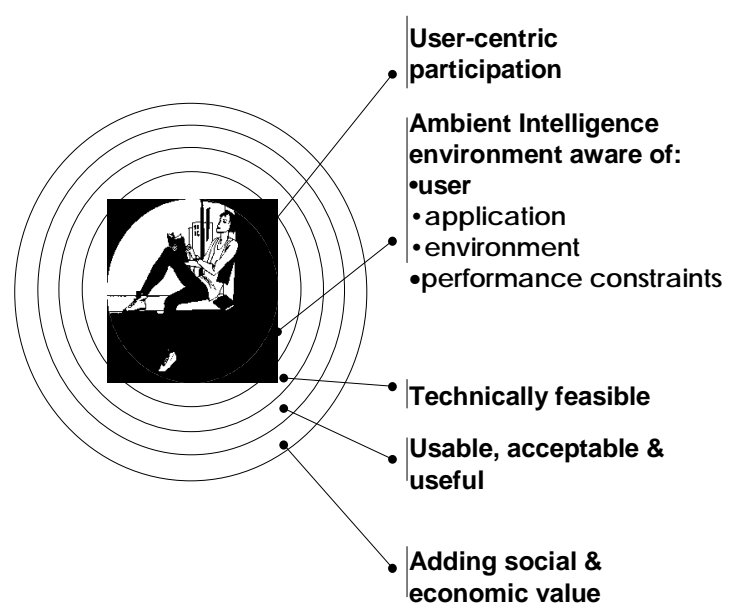

Figure 3. User-centred, participative, Ambient Intelligence

Source: ISTAG IST2003

be found to ensure the successful, seamless, integration of components and their convergence into Ambient Intelligence systems. There are a number of research domains or components in which significant progress must be made in order to further develop and realize the Ambient Intelligence vision. Table 1 indicates just some of the technologies for Ambient Intelligence that requires significant research.

\section{Table 1: Technology Areas Requiring Further Research for Ambient Intelligence}

Components for ambiance

Smart materials that can emit light efficiently; e.g. electronic wallpaper or large synthetic foils that can emit light, materials that can be used for touch and tactile movement, and synthetic materials that enable mass storage and processing of digital data, and that can be integrated into fabrics.

MEMS and sensor technology, including ultra low power (mechanical) effectuators, sensor devices bridging between the physical world and the cyber world, i.e., touch, vision, smell, and technology for the integration of smart materials, micro systems, and microelectronics into systems.

Embedded Systems development technology for re-configurable real-time embedded computing platforms, for remote diagnostics and repair of embedded systems, and to build in security and trustworthiness to embedded systems.

Ubiquitous communication including ubiquitous pico-radio networks for active and passive tagging, Internet accessibility for any physical object, and ubiquitous broadband access to content and data.

Input/Output device technology that supports ubiquitous hands-free speech control, ubiquitous touch pads and whiteboards, and can turn any surface into a display.

Adaptive software that is self-managing or has self-adjusting capabilities that can detect and adjust to the health or otherwise of its environment, re-allocating resources as required and automating much of the system configuration work that now has to be done manually.
Components for Intelligence

edia management and handling including presentation languages that support "produce once" and "present anywhere", methods and tools to analyse content and enrich it with metadata, and tools to exploit the Semantic

Natural interaction that combines speech, vision, gesture, and facial expression into a truly integrated multimodal interaction concept, allows human beings to interact with virtual through physical objects, and that enables people to navigate the seemingly infinite information they will be able to access.

Computational intelligence including conversational search and dialogue systems, behavioural systems that can adapt to human behaviour, and computational methods to support complex search and planning tasks.

Contextual awareness, for instance systems support navigation in public environments, ie. traffic, in airports and in hospitals, service discovery systems that enhance the shopping experience, and context aware control and surveillance systems.

Emotional computing that models or embodies emotions in the computer, and systems that respond to or recognise the moods of their and systems that can express emotions. 
Eventually Ambient Intelligence will enable the formation of virtual enterprises, the fluid configuration of business processes, and the seamless inter-operation of underlying information systems. This will support organizations that are willing and able to accept organisational changes to participate in several networks simultaneously without the need to radically alter their company cultures and preferred methods of working. Whether people respond positively to the opportunities presented by Ambient Intelligence will depend heavily on the extent to which Ambient Intelligence complements rather than replaces existing methods of work and social discourse and the extent to which it requires fundamental changes to organizational structures. Therefore, Ambient Intelligence must be conceived holistically and as it needs to be realized through highly complex systems. Performing specific research, embodying results in particular technologies and products, and then seek to commercialize those products is an obsolete development process. The technical complexity of modern systems based on ICTs requires that all aspects of the innovation chain integrate their efforts and hence the engagement of both the research and business communities to integrate the rapid co-evolution of the technology, the market, and social and administrative requirements that are critical for success (ISTAG 2003).

\section{Strategies for E-tourism in the Future}

ICTs have profound implications for tourism and etourism reflects the digitization of all processes and value chains in the tourism, travel, hospitality and catering industries. Tactically, e-tourism enables organizations to manage their operations and undertake e-commerce. Strategically, e-tourism revolutionizes business processes, the entire value chain as well as strategic relationships with stakeholders. E-tourism determines the competitiveness of organizations by taking advantage of intranets for reorganising internal processes, extranets for developing transactions with trusted partners and the Internet for interacting with all stakeholders (Buhalis 2003). ICT developments generate both opportunities and challenges for tourism organizations and the most significant emerging trends can be examined within the framework of change (Figure 4). Increasingly, tourism organizations need to use ICTs to develop strategies that are customer centric, profitability driven and partnership enabled. This will assist them to focus on their customers, organizational needs and distribution strategies respectively.

\section{Consumer-centric Approach}

ICTs should place users in the middle of its functionality and product delivery. Every tourist is different, carrying a

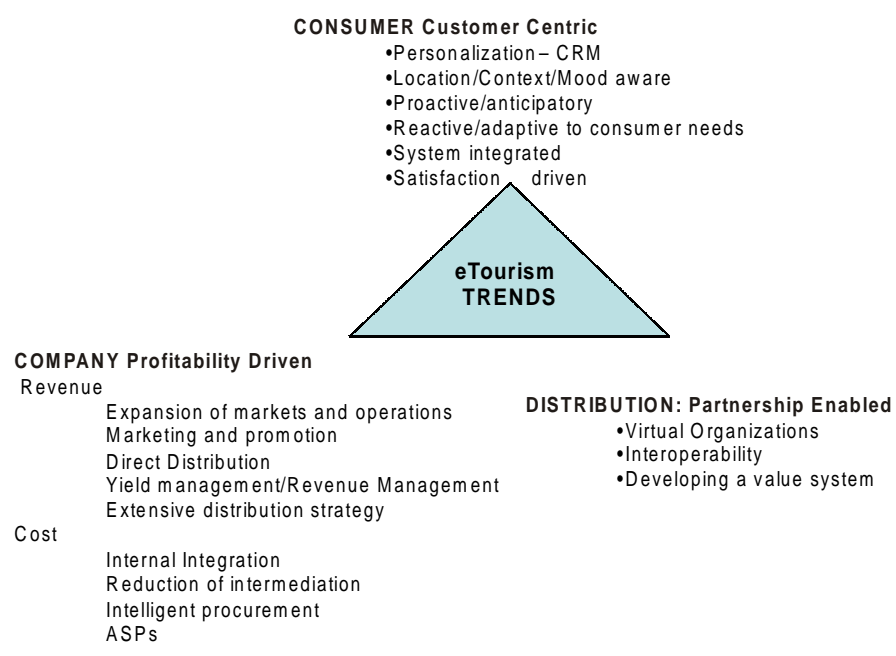

Figure 4. ICT enabled e-Tourism Trends

unique blend of experiences, motivations and desires. The population in general is travelling more frequently, becoming more linguistically and technologically skilled and can function in multicultural and demanding environments overseas. The Internet empowers such 'new' tourists with more knowledge, and encourages them to seek exceptional value for money and time. Experienced, sophisticated, demanding travellers require interaction with suppliers to satisfy their specific needs and wishes. Living a hectic life, consumers have shorter periods of time to recharge batteries and to engage in their favourite activities. Leisure time is used more for 'edutainment', (the exploration of personal interests for both personal and professional development) and independently organized tourism facilitated by dynamic packaging, whilst rigidly packaged mass tours are in decline. The contemporary/connected consumer is far less willing to wait or put up with delays, to the point where patience is a disappearing virtue. Hence the key to success lies in the quick and accurate identification of consumer needs and in reaching potential clients with comprehensive, personalized and up-to-date products and services that satisfy those needs.

Tourism organizations need to develop technologysupported personalized services to address individual needs. They should collect customer information at each stage of service - before, during and after a visit - in order to better understand consumer behaviour choices, concerns and determinants. Personalized services driven by advanced Customer Relationship Management systems should record customer preferences and requirements for present and future usage. Systems need to be location, context and mood aware, in order to provide sensible advice. Proactive services may be offered based on the anticipated needs obtained from 
known/declared or previously experienced customer profiles. Reactive services should be designed to meet the needs of customers following incidents or external environment factors. To achieve customer centricity, organizations need to integrate their systems and develop mechanisms for both recording customer reaction to stimulus and also to develop tools to allow consumers to customize their desired products to personal preferences.

Customer satisfaction depends highly on the accuracy and comprehensiveness of tourism information and the ability of organizations to provide tools for customization. Consumers not only require value for money, but also value for time for the entire range of their dealings with organizations. ICTs enable travellers to access reliable and accurate information as well as to undertake reservations in a fraction of time, cost and inconvenience required by conventional methods. Transparency between product characteristics and pricing also empower customers. ICTs can assist the customization of service quality and contribute to higher guest/traveller satisfaction. Consumers can personalize not only their choice of products but also the essence of the product itself by customizing the layout of hotel rooms, the channels available on the TV or the drawings on the wall. A wide range of developments empower consumers, as indicated in Figure 5.

- User friendly and customised interfaces (e.g., MyHilton);

- Consumers have more information and enjoy greater choice;

- Accurate and richer marketing research by collecting data from all transactions and enquiries

- Better understanding of consumer needs based on research interaction and data mining;

- Differentiated and customized services according to personal preferences and attitudes;

- Pricing becomes more flexible and transparent;

- Reduction of bureaucracy and paper-work frees employee time for better customer service;

- Customizing the product and establishing "one-to-one" marketing through loyalty schemes ;

- New personalized value added services (e.g., personalized inflight or in-room entertainment and information channels);

- Automation of repetitive operational tasks through ITs (e.g., inroom TV checkout);

- Personalized services (e.g., telephone operator acknowledges guest by name or waiter knows dietary preferences or requirements);

- Language barriers reduced through interfaces that markets through automatic translations

Figure 5. IT Empowered Developments Enhancing Customer Satisfaction
Powerful databases, supported by innovative Decision Support Systems, should therefore drive organizations to personalize services and to match consumer needs with organizational capabilities and offerings. ICT-supported, consumer-centric, flexible service delivery is critical and the industry needs to become more flexible, efficient and quicker in responding to consumer requests as well as to offer ICTs tools and mechanisms for product customization.

\section{Profitability Driven}

Tourism is a profit driven industry and ICTs should contribute to profitability. This can be achieved through driving increases in revenue, reductions of production and operational cost and increase of awareness and promotion. Emerging tools can support production increase, improvement of load factor/occupancy levels and enhance scheduling. Airlines for example, use technology to forecast demand, schedule and monitor load factors before deciding on route capacity, frequency, hub and spoke operations. Other types of organizations can similarly manage capacity more efficiently as well as expand to new markets using similar ICT based tools. ICTs also facilitate direct distribution - a critical function for increasing revenue. By distributing directly organizations can save commission and fees and reinforce their brand throughout the process, engage with consumers, satisfy personalized needs and better understand consumer preference and price elasticity. Selling products directly also increases customer loyalty and reduces leakages to competing organizations.

Technology empowered Yield/Revenue Management support accurate demand estimates and decisions to either fluctuate capacity (in the case of transportation) and/or price to optimise revenue. Yield management is about coordinating 5Cs: calendar, clock, capacity, cost and customer. Strategically, levels of yield management are geared to matching service timing and pricing to customers' willingness to pay in relation to its timing and demand from other customers (Enz and Withiam 2001). Historical demand patterns, competitor pricing as well as events and occurrences affecting demand can be scanned electronically to provide revenue-management critical information. Constant interactivity with consumers and partners enables flexible and competitive pricing. Monitoring sales allows marketers to adjust the product and price or/and to initiate promotional campaigns. ICTs can also alert organizations about excess capacity or demand. Multi-location organizations (e.g., tour operators or airlines) can then divert capacity to profitable segments or regions. On-line auctions and last minute offers can provide additional revenue streams and new avenues for disposing distressed capacity. Specialist organizations such as lastminute.com and 
QXL.com have developed their entire business model around this proposition and dispose of distressed inventory without spoiling suppliers' brands.

Tourism organizations can also use ICTs for building awareness and promotion through newsletters, pop-ups and search engine optimization strategies. Regardless of size they can build and maintain web sites, either internally or through partners. ICTs enable tourism organizations to have a global presence and partnerships around the world in an efficient and cost effective manner enabling small firms to build their virtual size. Until recently Global Distribution Systems (GDS) were the only widely spread electronic distribution channel, despite being limited to the distribution of scheduled airlines, city hotel chains and large car rental companies. The Internet enables all types of organizations to distribute products directly to consumers and to link with emerging intermediaries (such as Lastminute.com, Expedia, eBookers and Hotels.com) expanding their value chain and promote their products through a combination of systems and partners (Buhalis and Licata 2002; O'Connor 2003; Kärcher 1997).

Despite expensive initial investments, ICTs can reduce administration and production costs by integrating internal data and processes. Operational and communication costs can be reduced by integrating operational systems, maximizing internal efficiencies, decreasing back office labour costs, reducing number and length of personal communications, and enabling consumers to have direct access to information. Disintermediation and reduction of commission and fees for intermediaries also reduces costs. Despite the cost of developing e-Commerce platforms, many firms achieved savings by direct distribution. Many have passed a proportion of savings to consumers to maintain competitiveness. As more consumers are able to serve themselves online, the distribution costs are declining. On the procurement side, organizations will increasingly purchase products from global electronic marketplaces. Systematizing the procurement function, through electronic connections with regular suppliers, can also reduce processing and administration costs. Finally, Application Service Providers (ASPs) allow organizations to 'rent' ICT applications developed and hosted by specialized professionals (Paraskevas and Buhalis 2002). This enables them to share the development and maintenance cost of such software. Hence, ICTs should contribute to profitability through increase of revenue and reduction of costs.

\section{Enabled Partnerships}

Few other industries depend on partnerships as much as tourism. ICTs empower networking throughout the industry and also improve the interactivity between tourism production and distribution partners, supporting a closer cooperation towards the provision of wide ranging products.

The creation and delivery of tourism products is based on partnerships between a range of organizations, including: transportation, accommodation, catering, entertainment and cultural heritage. Taking advantage of the characteristics of virtual reality, organizations will force firms to adapt their product constantly to satisfy tourism demand; use information extensively; develop partnerships; and outsource a significant amount of functions in order to achieve economies of scope (Hale and Whitlam 1997). Virtual organizations will allow tourism firms to develop extended products and services, produced independently and instantaneously, in response to customer demand. Informational networks can link up and bring together the core competence of independent firms breaking traditional organizational boundaries. Trusted partners can offer flexible and speedy value added products and services, through accessing world-class competencies, exploiting fastchanging opportunities by sharing costs, skills, and by accessing global markets. These corporations do not necessarily need to be located near the consumer, as ICT networks and tools empower corporations to develop a virtual proximity to consumers and their needs.

Networking allows the outsourcing of non-core functions to specialists, whilst value added services and products can be sourced from competent trusted partners. Distribution is the obvious function that benefits from virtual organizations. The globalization of the industry intensifies the information required for all tourism transactions and requires instant confirmation and purchasing abilities. As distribution has changed from facilitation of information exchange and reservations to a sophisticated mechanism for dynamic personalization of added value services, virtual corporations enable tourism firms to expand their value chain and include endless products and services. Intermediaries have access to endless inventory whilst suppliers become intermediaries by augmenting their product by selling complementary products and services from partners. Organizations need therefore to appreciate the benefits of co-opetition and co-destiny, when organizations need to collaborate with players that they would normally regard as competitors.

Virtual corporations and globalization bring more market participants and complicate distribution channels further (Figure 6) increasing heterogeneity and requiring standardization and inter-connectivity. The virtualization of the tourism value chain will depend on the degree of 
interconnectivity and interoperability between organizations to allow the flow of information and data in this complex value process. To ensure interoperability, data from a variety of independent sources has to be collated and delivered to final users and distribution systems in a consistent format. Hitherto a number of standardization initiatives [such as IFITT Reference Model Special Interest Group (RMSIG), Hospitality Industry Technology Integration Standards (HITIS), Open Travel Alliance (OTA) and the Travel Technology Initiative (TTI), the Hotel Electronic Distribution Network Association (HEDNA) and Hotel Technology - Next Generation] have developed standards to promote communication between different data structures and organizations. However, these programmes have faced adoption challenges in different countries and cultures. Moreover, standardization initiatives are in general being driven by the big players in the market and SMEs have little or no choice but to adopt the changes, irrespective of their suitability, or risk being left behind. There is a need for a common tool that allows organizations to recognize and to communicate with each other allowing wide interoperability.

The advent of new technical frameworks (XML, Semantic integration) raises new expectations on the integration process. Semantic reconciliation tools are being developed, such as a data mediator computer programs that translates data between systems with different data exchange formats/schemas. This approach depends on a shared, conceptual reference schema: the ontology of the domain and allows individual organizations to keep their proprietary data format whilst exchanging information based on the ontology (Missikoff et al. 2003; Fodor and Werthner 2005). A mediation tool is based on three major technologies: XML, for information coding and exchange; ontology, for knowledge and content management; integration of 'heterogeneous information sources', for the reconciliation method. The mediator automatically generates

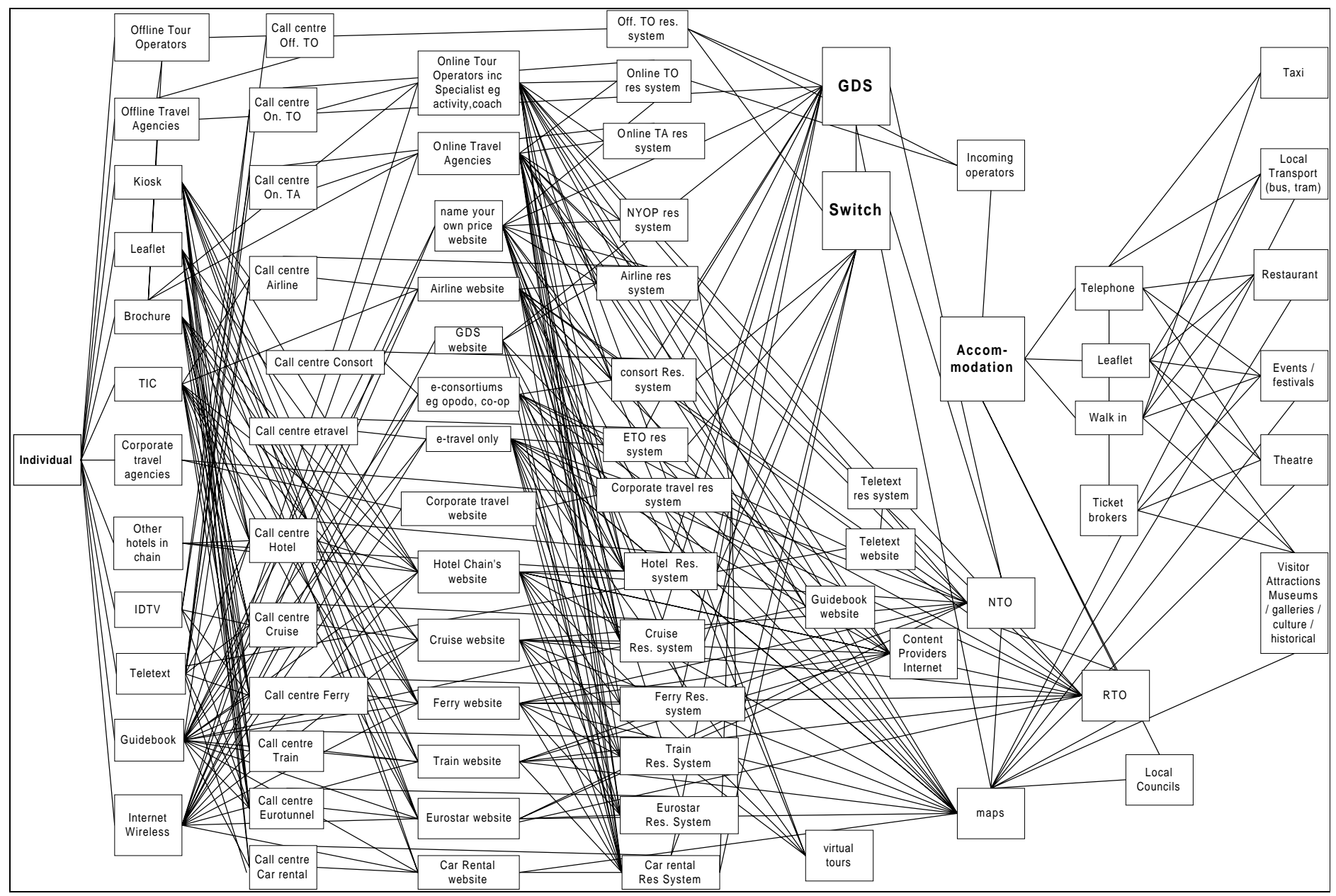

Figure 6. Interconnectivity in Tourism 
data translations from descriptions of the data in the source and the receiver schemas, allowing users to keep their proprietary data formats whilst allowing interaction among their data.

ICTs increasingly transform distribution to a global value system, where access to information and ubiquity is achieved, while interactivity between principals and consumers provides major opportunities. Hence, the Internet propels the re-engineering of the entire process of producing and delivering tourism products, as well as it boosts interactivity between partners that can design specialized products and promotion in order to maximize the valueaddition provided to individual consumers. Ultimately, ICT tools reinvent the packaging of tourism to a much more individual-focused activity, offering great opportunities for principals and intermediaries and enhancing the total quality of the final product (fitness to purpose). Equally, it is changing the structure of the industry to an ecosystem of individual but interrelated organisms and nodes all interconnected and interoperable.

\section{Conclusions}

\section{IT trends and Implications for Tourism}

ICTs evolve constantly, providing new tools for tourism marketing and management. They support the interactivity between tourism enterprises and consumers and as a result they re-engineer the entire process of developing, managing and marketing tourism products and destinations. This paper has identified a number of key changes in hardware, software and networking that will impact on the tourism industry in the future. Although the exact impacts are far from clear, the future of e-Tourism will be focused on 'consumer centric' technologies that will enable organizations to focus on their profitability through a network of partnerships. Consumers will be more sophisticated and experienced and, therefore, more difficult to please. The availability of powerful ICTs empowers both suppliers and destinations to enhance their efficiency and re-engineer their communication strategies. Increasingly, ICTs will provide the 'info-structure' for the entire industry and will take over all mechanistic aspects of tourism transactions. Innovative tourism enterprises will have the ability to divert resources and expertise to servicing consumers and provide higher value-added transactions. Agile strategies are required at both strategic and tactical management levels to ensure that the ICT raised opportunities and challenges are turned to the advantage of tourism organizations to enhance their innovation and competitiveness.

\section{Acknowledgement}

A version of this paper will be published in Tourism Management Dynamics, edited by Dimitrios Buhalis and Carlos Costa 2005. Permission to publish this article has been granted by Elsevier Sciences.

\section{References}

AMOR, D. (2002). Internet Future Strategies. New Jersey. Prentice Hall.

BEEKMAN, G. (2003). Computer Confluence: Exploring Tomorrow's Technology, $5^{\text {th }}$ ed. New Jersey. Prentice Hall.

BUHALIS, D. (1998). Strategic Use of Information Technologies in the Tourism Industry. Tourism Management 19(3): 409-423.

BUHALIS, D. (2003). E-Tourism: Information Technology for Strategic Tourism Management. Cambridge. Pearson.

BUHALIS, D. and LICATA, C. (2002). The Future of e-Tourism Intermediaries. Tourism Management 23(3): 207-220.

ENZ, C. and WITHIAM, G. (2001). Yield Management. CHR Reports. Itacha. Cornell University.

EU (2001). The Development of Broadband Access Platforms in Europe: Technologies, Services, Markets, Final Report Information Society. Brussels. IST, European Commission.

FODOR, O. and WERTHNER, H. (2005). Harmonise: A Step Towards an Interoperable e-Tourism Marketplace. International Journal of Electronic Commerce 9(2): 11-39.

HALE, R. and WHITLAM, P. (1997). Towards the Virtual Organisation. London. McGraw-Hill International.

ISTAG (2003). Ambient Intelligence: From Vision to Reality for Participation - In Society and Business. IST Advisory Group. Draft Report. Brussels. IST, European Commission.

KÄRCHER, K. (1997). Reinventing Package Holiday Business. Berlin. Deutscher Universitäts.

MISSIKOFF, M., WERTHNER, H., HÖPKEN, H., DELL'ERBA, M., FODOR, O., FORMICAA, A. and TAGLINOA, F. (2003). Harmonise Towards Interoperability in the Tourism Domain. In Frew, A., Hitz, M. and O'Connor, P. (Eds.) Information Communication Technologies in Tourism. Vienna. Springer Verlag.

O'CONNOR, P. (1999). Electronic Information Distribution in Tourism Hospitality. Oxford. CABI.

O'CONNOR, P. (2003). Online Intermediaries - Revolutionizing Travel Distribution, EIU Travel and Tourism Analyst. London. Thomson.

PARASKEVAS, A. and BUHALIS, D. (2002). Information Communication Technologies Decision-making: The ASP Outsourcing Model from the Small Hotel Owner/Manager Perspective. The Cornell Hotel Restaurant Administration Quarterly 43(2): 27-39. 
POON, A. (1993). Tourism, Technology and Competitive Strategies. Oxford. CAB International.

SHELDON, P. (1997). Information Technologies for Tourism. Oxford. CAB International.

WERTHNER, H. and KLEIN, S. (1999). IT and Tourism: A Challenging Relationship. Vienna. Springer Verlag.

Submitted: January 7, 2005

Revised: July 22, 2005

\section{Subscriptions Alert}

Name of Publication

Schedule of Publication

ISSN No.

Publisher
- Tourism Recreation Research

- Thrice a year (April - August - December)

- 0250-8281

- Tej Vir Singh

Centre for Tourism Research and Development

(A not-for-profit organization)

A-965/6, Indira Nagar, Lucknow 226 016, India

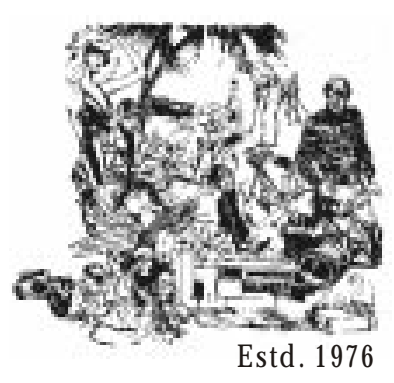

\section{Ovserseas Subscription Information (from 2006 on wards)}

- Current Volume (3 issues) at US \$220

- Current Volume (single issue) at US $\$ 75$

- Back Volumes are available at a discount on current prices.

\section{Indian Subscription In form ation (from 2006 onwards)}

- Current Volume ( 3 issues) at INR 2400

- Current Volume (single issue) at INR 800

- Back Volumes are available at a discount on current prices.

\section{For details contact:}

Subscriptions-in-Charge

TOURISM RECREATION RESEARCH

A-965 / 6 Indira Nagar, Lucknow - 226016, U.P., India

Tele-fax: +91522 2340313

e-m ail: tvsingh@sancharnet.in, W ebsite: www.trrw orld.org

Note : Subscription payments are non-refundable

Claims valid within four months of the print schedule. 